\title{
Investigation of the stabilization of verdigris-containing rag paper by wet chemical treatments
}

\author{
Kyujin Ahn ${ }^{1}$, Andreas Hartl ${ }^{2}$, Christa Hofmann ${ }^{2}$, Ute Henniges ${ }^{1}$ and Antje Potthast ${ }^{1 *}$
}

\begin{abstract}
Copper pigments promote the deterioration of paper objects; hence, it has been problematic to paper conservation since many valuable historical manuscripts contain copper green pigments. In particular, verdigris yields relatively mobile copper ions that can cause a higher risk of degradation depending on the relative humidity of the storage conditions. Although several research studies have demonstrated potential chemicals to slow down the degradation of the paper with copper ions or copper pigments, passive treatments such as mechanical reinforcement or environmental controls are still preferred since wet chemical treatments need to be further investigated. In the present study, various wet chemical treatments of rag paper with verdigris are tested with consideration for the practical situations of application as well as the sample conditions. GPC-Fluorescence-MALLS system after fluorescence labeling of carbonyl groups of cellulose was employed to evaluate the inhibition of both, hydrolysis and oxidation of cellulose after treatments. Samples were prepared to simulate a partially soluble verdigris pigment bound in gum arabic on gelatin-sized rag paper.

With the given sample conditions, beneficial effects from deacidification was rather limited despite the use of a mixture of water and ethanol as a co-solvent. In contrast, treatments with tetrabutylammonium bromide in ethanol or $1 \mathrm{H}$-benzotriazol in ethanol showed significant stabilization of the samples. For both cases, hydrolytic degradation and oxidation of cellulose were retarded significantly when brushing application on verso was employed. Testing various conditions of the solutions and two different application methods led to the conclusion that the outcome of the solution treatment depends on not only the chemical, but also how it is applied.
\end{abstract}

Keywords: Rag paper, Verdigris, Copper-catalyzed degradation, Cellulose, Stabilization, GPC, Deacidification, Tetrabutylammonium bromide, Benzotriazole

\section{Introduction}

Paper objects with copper pigments are threatened since copper ions that migrate from the pigments can cause the accelerated degradation of cellulose and discoloration of the paper. In severe cases, the paper is so fragile that even handling of the object becomes critical. Major parameters for the severe degradation of paper in the presence of copper acetate pigment (verdigris) found in historic objects remain unclear due to a variety of parameters of the paper substrates as well as of verdigris bound in an organic medium and the usually unknown storage conditions.

\footnotetext{
*Correspondence: antje.potthast@boku.ac.at

'Department of Chemistry, University of Natural Resources and Life Sciences, Muthgasse 18, 1190 Vienna, Austria

Full list of author information is available at the end of the article
}

Several studies show that oxidation is a dominant degradation pathway of cellulose when copper(II) is present compared to iron(III), which mainly causes hydrolysis in the acidic conditions [1,2]. The formation of reactive oxygen species catalyzed by the presence of copper ions, which may cause further radical chain reactions, was detected $[3,4]$. The catalytic activity of copper in the generation of hydroxyl radicals is higher than that of any other transition metals at $\mathrm{pH} 7$ [5]. Its activity is highly dependent on $\mathrm{pH}$ : when the $\mathrm{pH}$ is higher than $\mathrm{pH} 7.5$, the rate of formation of hydroxyl radicals increases greatly in the presence of $\mathrm{Cu}(\mathrm{II})$ [5].

The extensive production of hydroxyl radicals due to the presence of copper ions under alkaline conditions may lead to a need for caution in deacidification treatments of

\section{() Chemistry Central}


copper pigment-containing papers. Thus, an additional treatment with an antioxidant that reacts as a radical scavenger or peroxide decomposer is often recommended when copper compounds are present [6,7]. In particular, halide antioxidants were found to be effective in reducing the generation of hydroxyl radicals $[8,9]$. For verdigriscontaining paper, tetrabutylammonium bromide (TBAB) with or without calcium hydrogen carbonate was found to be positive as a result of visual assessment [10]. Ethyl methylimidazolium bromide with non-aqueous deacidification using a Bookkeeper ${ }^{\mathrm{TM}}$ spray [11] and non-aqueous magnesium propylate mixed with alkyl $p$-hydroxybenzoate as antioxidant [12] also yielded retardation of cellulose degradation.

The use of a chelating agent as a remedial chemical for copper pigment-containing paper was also tested. A short-chain gelatin and the recombinant protein isolated by immobilized metal ion affinity chromatography (IMAG) showed inhibition of copper pigment corrosion, indicating potential for the formation of a stable complex with copper (II) ions [13]. Calcium phytate treatment in combination with calcium hydrogen carbonate, which has become a secure conservation treatment for iron-gall ink-containing paper, could also stabilize the paper even when it contains additional copper ions $[6,14]$, which raises speculation regarding the possible chelating of phytate with copper ions. The concept of complexing copper ions using 1H-benzotriazol (BTA) has also been proposed [15]. $1 \mathrm{H}$-benzotriazol has been known as one of the best copper corrosion inhibitors for metallic objects. Its low vapor pressure at room temperature and solubility in water as well as in alcohol can widen its application for $\mathrm{Cu}$-containing paper.

Concerning deacidification treatment, despite the high catalytic activity of $\mathrm{Cu}$ (II) under alkaline conditions, alkaline earth carbonates still bring about the stabilization of copper-catalyzed degradation of paper. In particular, magnesium hydrogen carbonate treatment consistently resulted in a good contribution to the stabilization of copper-containing paper $[4,16,17]$. Not only does neutralization take place but a beneficial effect of magnesium ions also seems to occur. Non-aqueous deacidification treatments, which can readily deposit more magnesium carbonate and a higher $\mathrm{pH}$ than aqueous deacidification treatments [18], also gave rise to a potential treatment for copper pigment-containing paper [12].

Based on the theoretical and empirical backgrounds described above, various wet chemical treatments of rag paper with verdigris were tested, simulating a practical situation that conservators might face in their workshops. The sample paper was a handmade rag paper with gelatin sizing, and the verdigris pigments bound in gum arabic were still partially soluble in water or alcohols. The tested chemicals include alkaline earth carbonates and hydroxide, complexing agents such as calcium phytate and $1 \mathrm{H}$ benzotriazol, and antioxidants such as tetrabutylammonium bromide and ethyl $p$-hydroxybenzoate. Mostly, a single chemical treatment was employed to focus on the effect of each agent, with a few exceptions, such as a two-step calcium phytate/calcium hydrogen carbonate treatment. The stabilization effect of the treatments was evaluated by the GPC-Fluorescence-MALLS system with fluorescence labeling of the oxidative functionality of cellulose after accelerated aging. Using this system, not only absolute molar mass moments determined by MALLS (multi-angle laser light scattering detector), but also the carbonyl group contents measured by a fluorescence detector after a carbonyl specific labeling could be presented. Analysis of selected samples using SEM-EDS was also performed. In this paper, the effect on the molecular structure of cellulose, i.e. molar mass and carbonyl groups, after accelerated aging are discussed to evaluate the stabilization of cellulose after different treatments in the presence of copper ions. Details of visual changes after treatments and after accelerated aging and the aspects of practical application by conservators are introduced elsewhere.

\section{Experimental}

\section{Sample preparation}

Hand-made rag paper was chosen as a model paper since most of manuscripts with verdigris to be treated are made of rag paper. Rag paper was obtained from Gangolf Ulbricht Papierwerkstatt, Berlin, Germany. It was made of linen and hemp pulp and gelatin sized with alum. Its grammage was around $80 \mathrm{~g} / \mathrm{m}^{2}$. Finely ground copper acetate verdigris pigment (product no. 44450 by Kremer Pigmente GmbH, Germany) mixed with gum arabic (product no. 63320 by Kremer Pigmente $\mathrm{GmbH}$, Germany) (pigment: $20 \% \mathrm{w} / \mathrm{v}$ of gum arabic in water: water $=1: 2: 1)$ was brushed onto an area of $50 * 60 \mathrm{~mm}$ of the rag paper using the glass rod application method and a brushing application. The glass rod application was carried out by dragging the paint applied on a thin film of polyester onto the rag paper quickly and evenly with a glass rod. For the brushing application of the paint, the paint was brushed on the area of interest after testing the brushing performance to paint the entire area evenly. The sample was air-dried and conditioned at $80 \%$ $\mathrm{RH}$ for 30 minutes in a humidity chamber and then flattened using blotters, felts, and weights.

Pre-aging of the prepared rag paper with verdigris paint was performed to simulate degraded paper and to reduce the water sensitivity of the pigment before applying the wet chemical treatment (Figure 1). The selected preaging method was light aging, determined according to a preliminary aging study [19]. Light can act as a means to accelerate copper-catalyzed degradation of cellulose based 


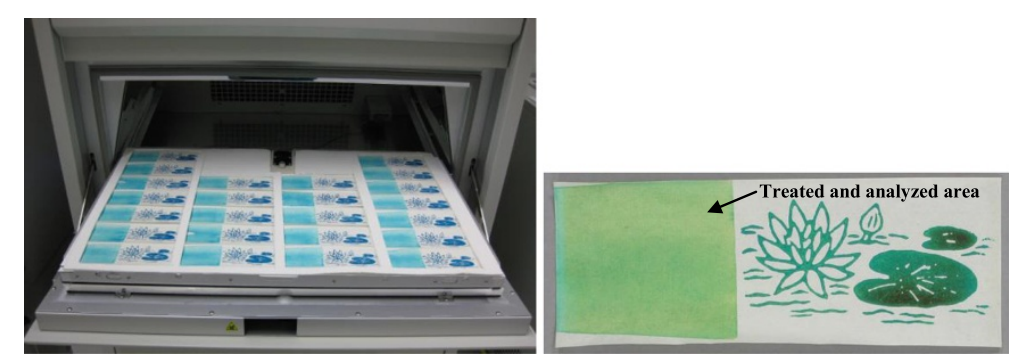

Figure 1 Pictures of samples. Left - rag paper samples with verdigris just before applying pre-aging. Right - one sample after pre-aging, i.e., before treatment.

on our observation of many original cases of manuscripts with verdigris. The recto of the samples was irradiated. The paint layer on the analyzed area was thin enough so that the paper substrate with copper ions was exposed to light. A Q-Sun Xe-3 Tester (Q-LAB, USA) facilitated with xenon lamps and UV filters was used under the following conditions: 10 cycles of 12 hours of light exposure at $1.10 \mathrm{~W} / \mathrm{cm}^{3}$ at $50 \% \mathrm{RH}$ and $38^{\circ} \mathrm{C}$ and 4 hours of reconditioning in the dark at $23^{\circ} \mathrm{C}$ and $50 \% \mathrm{RH}$. The location of samples was rotated every day during aging to induce even exposure of the light to the samples. After pre-aging, $20-35 \%$ of $\mathrm{Mw}$ loss was found, and the carbonyl group contents increased from around $4 \mu \mathrm{mol} / \mathrm{g}$ to $17-22 \mu \mathrm{mol} / \mathrm{g}$ depending on the batches of sample preparation.

\section{Stabilization treatments}

Schematic testing procedures for chemical treatments are illustrated in Figure 2. The treatments started with various chemical solutions sprayed on a suction table based on preliminary tests, survey results, and literature. Chemicals and application methods were modified or eliminated over several screening steps depending on the results of GPC analysis, visual inspection, practicality in a general conservation workshop, and literature. Detailed

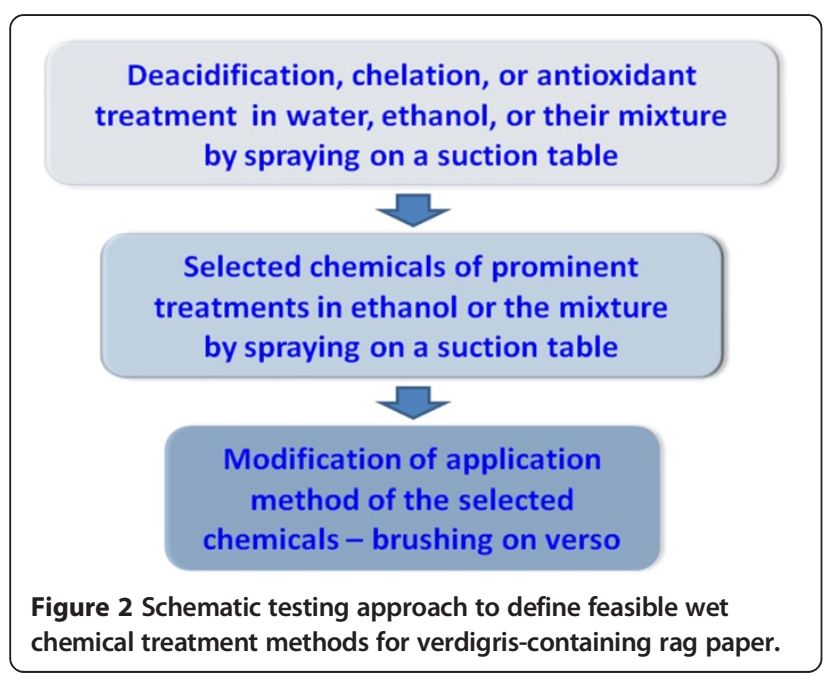

information on the chemicals and application methods tested in the present study is shown in Table 1. All treatments were carefully conducted by professional paper conservators. For the spraying application, $45-50 \mathrm{ml}$ of treatment solution was sprayed onto the sample on a suction table placing a blotting paper (Canson) and a thin polyester web (Parafilm RT30) between the sample and the suction table. The brushing application was performed by brushing four strokes of the solution on the verso of the sample after optimization tests of its penetration depth as well as of its homogeneous application. The floating application was carried out only for one sample with calcium hydrogen carbonate. The sample was placed on a polyester screen and floated on the solution.

\section{Post-accelerated aging after treatments}

Two different accelerated aging methods were applied after treatment. One was humid thermal aging, the conditions of which were $80^{\circ} \mathrm{C}$ and $65 \%$ of RH. Sample papers were stacked between lining papers and aged in an accelerated aging chamber based on ISO 5630-3:1996 [22]. The total aging duration for humid thermal aging varied from 7 days to 13 days depending on the testing batch. The other accelerated aging was light aging. Its conditions were exactly the same as the pre-aging conditions. Eighteen cycles of exposure and reconditioning were applied.

\section{Migration test of copper ions in BTA-impregnated paper}

Rag paper and Whatman no.1 paper were immersed in $1.7 \%(\mathrm{w} / \mathrm{v})$ of $1 \mathrm{H}$-benzotriazol (BTA) in a mixture of water and ethanol (2:1) for 30 minutes. They were dried under ambient conditions after removing the excess BTA solution between blotting papers (natural white acid-free, product no. 04001 by KLUG Conservation, Germany). Verdigris bound in gum arabic (pigment: gum arabic $20 \% \mathrm{w} / \mathrm{v}=1: 1 \mathrm{v} / \mathrm{v}$ ) was printed on several spots of the prepared BTA-impregnated papers. The verdigris paint was also printed on untreated papers and papers that had been immersed in only a mixture of water and ethanol for the same duration without BTA as control samples. 
Table 1 Chemicals and application methods tested

\begin{tabular}{|c|c|c|c|}
\hline & Chemical & Details & Application methods \\
\hline \multirow{2}{*}{ Blank carrier } & Water & Deionized & Spraying on a suction table \\
\hline & Ethanol & $96 \%$ & Spraying on a suction table \\
\hline \multirow{4}{*}{ Deacidification } & $\begin{array}{l}\text { Calcium hydrogen carbonate in } \\
\text { water and ethanol mixture }(2: 1)\end{array}$ & $<0.012 \mathrm{M}$ in water diluted with ethanol & $\begin{array}{l}\text { Spraying on a suction table, } \\
\text { brushing on the verso }\end{array}$ \\
\hline & $\begin{array}{l}\text { Calcium hydroxide in water and } \\
\text { ethanol mixture (2:1) }\end{array}$ & $\begin{array}{l}\text { Saturated solution diluted to } \mathrm{pH} 9.3 \text { with } \\
\text { water and then mixed with ethanol }\end{array}$ & Spraying on a suction table \\
\hline & $\begin{array}{l}\text { Magnesium hydrogen carbonate in } \\
\text { water and ethanol mixture }(2: 1)\end{array}$ & $<0.012 \mathrm{M}$ in water diluted with ethanol & $\begin{array}{l}\text { Spraying on a suction table, } \\
\text { brushing on the verso }\end{array}$ \\
\hline & Magnesium propylate ${ }^{*}$ in 1-propanol & $5 \% \mathrm{v} / \mathrm{V}$ & $\begin{array}{l}\text { Spraying on a suction table, } \\
\text { the same as without suction }\end{array}$ \\
\hline \multirow{2}{*}{ Antioxidant } & $\begin{array}{l}\text { Tetrabutylammonium bromide } \\
\text { (TBAB) in ethanol }\end{array}$ & $0.03 \mathrm{M}(\sim 1 \% \mathrm{w} / \mathrm{v})$ & $\begin{array}{l}\text { Spraying on a suction table, } \\
\text { brushing on the verso }\end{array}$ \\
\hline & $\begin{array}{l}\text { Ethyl } p \text {-hydroxybenzoate (PHB) in } \\
\text { ethanol }\end{array}$ & $0.2 \%, 1 \% \mathrm{w} / \mathrm{V}$ & $\begin{array}{l}\text { Spraying on a suction table, } \\
\text { brushing on the verso }\end{array}$ \\
\hline \multirow{3}{*}{ Complexation } & 1H-benzotriazole (BTA) in ethanol & $5 \%, 0.5 \%, 3 \% \mathrm{w} / \mathrm{v}$ & $\begin{array}{l}\text { Spraying on a suction table, } \\
\text { brushing on the verso }\end{array}$ \\
\hline & $\begin{array}{l}\text { Two step-calcium phytate/calcium } \\
\text { hydrogen carbonate treatment }\end{array}$ & $\begin{array}{l}1.75 \mathrm{mM} \mathrm{Ca} \text { phytate in water followed } \\
\text { by } 0.012 \mathrm{M} \mathrm{CaCO}_{3} \text { in water }\end{array}$ & Spraying on a suction table \\
\hline & $\begin{array}{l}\text { Modified calcium phytate }{ }^{* * *} \text { in a } \\
\text { mixture of water and ethanol }(2: 1) \\
\text { (M-Ca phytate) }\end{array}$ & $\begin{array}{l}1.75 \mathrm{mM} \text { Ca phytate in water and } \\
\text { ethanol }(2: 1)\end{array}$ & $\begin{array}{l}\text { Spraying on a suction table, } \\
\text { brushing on the verso }\end{array}$ \\
\hline
\end{tabular}

\footnotetext{
"The reagent was provided by PAL Preservation Academy GmbH Leipzig. 5\% (v/v) of the reagent in 1-propanol can deposit around 0.5\% w/w of MgCO in Whatman no. 1 paper by spraying.

${ }^{* *}$ References: $[20,21]$.

*** It was modified by adding a non-ionic surfactant mixture to increase solubility (stable suspension) of calcium phytate in water and ethanol mixture. Details will be presented elsewhere.
}

\section{Methods}

\section{Fluorescence labeling of carbonyl groups and GPC measurement}

The CCOA (Carbazole-9-Carbonyl-Oxy-Amine) labeling of carbonyl groups was performed as described earlier [23-25]. $25 \mathrm{mg}$ (wet weight) of each sample was taken for labeling and GPC analysis after disintegrating the whole painted area of the sample (around 300-400 mg) to produce a representative value for the treated area.

After the labeling of the samples, dissolution in $N, N$ dimethylacetamide/lithium chloride $9 \%(\mathrm{w} / \mathrm{v})(\mathrm{DMAc} / \mathrm{LiCl})$ was achieved via solvent exchange at room temperature. Measurements were performed with a GPC-FluorescenceMALLS system that yields in both cases the molar mass and the molar mass distribution in addition to the number and distribution of oxidized groups.

The GPC system used consists of a TSP FL2000 fluorescence detector for monitoring the CCOA label, a multiangle laser light scattering detector (MALLS) (Wyatt Dawn DSP with argon ion laser; $\lambda_{0}=488 \mathrm{~nm}$ ), and a refractive index detector (Shodex RI-71). Four serial GPC columns (Polymer Laboratories-current Agilent/Varian-PLgelmixedA LS, $20 \mu \mathrm{m}, 7.5 \times 300 \mathrm{~mm}$ ) were used as the stationary phase. A degasser (Dionex DG-2410), an autosampler (HP 1100), a pump (Kontron 420), and a column oven (Gynkotek STH 585) were also part of the system.
GPC was performed according to the following conditions: $1.00 \mathrm{ml} / \mathrm{min}$ flow rate, $100 \mu \mathrm{l}$ injection volume, 45-minute run time, $\lambda_{\mathrm{ex}}=290 \mathrm{~nm}$, and $\lambda_{\mathrm{em}}=340 \mathrm{~nm}$ for the fluorescence detection of the CCOA label. DMAc/LiCl $(0.9 \%, \mathrm{w} / \mathrm{v})$ after filtering through a $0.02 \mu \mathrm{m}$ filter was used as an eluant.

Data evaluation was performed with standard Chromeleon, Astra, and GRAMS/32 software. The error bars presented in each figure are based on the standard deviation of the samples prepared and pre-aged in a same batch before post-aging on the assumption that no significant change takes place immediately after treatment. Due to the inhomogeneity of the sample, the RSD (\%) of carbonyl groups in particular was on average $12 \%$.

\section{$\mathrm{pH}$}

$\mathrm{pH}$ measurement (cold extraction) was carried out with a semi-micro $\mathrm{pH}$ electrode (InLab ${ }^{\mathrm{Tm}}$ Semi-micro $\mathrm{pH}$ electrode, Mettler Toledo), as introduced by Strlič et al. [26]. The scale was reduced by 40 times to that required by TAPPI 509 om-02 [27]. According to the test results with Whatman no. 1 paper, RSD was $\sim 2 \%$ between measurements as well as between samples, which was found with the standard $\mathrm{pH}$ measurement method using an ordinary $\mathrm{pH}$ electrode $\left(\mathrm{InLab}^{\mathrm{\tau m}}\right.$ EASY $\mathrm{pH}$ electrode, Mettler Toledo). 


\section{SEM-EDS}

The deposition of calcium carbonate was examined with Hitachi S-4000 scanning electron microscopy (SEM) with energy-dispersive X-ray spectroscopy (EDS) at $15 \mathrm{kV}$ accelerating voltage after gold coating.

The paper structures of the sample rag paper and Whatman no.1 paper were examined with FEI Inspect S50 SEM at $10 \mathrm{kV}$ after approx. $15 \mathrm{~nm}$ of gold coating.

\section{Results and discussion}

\section{Hot and humid thermal aging}

\section{Influence of carrier solvents}

First, it is necessary to discuss the influence of water or ethanol on the sample since the verdigris paint used in this study was partially soluble, which means that the migration of copper ions took place by wet treatment. As expected, the pure water-treated sample tended to degrade more than the untreated control sample after thermal aging, while the pure ethanol-treated sample was comparable to the untreated control (Figure 3). When pure water and a mixture of water and ethanol were used as carriers of calcium hydrogen carbonate, the same trend was found. Pure aqueous treatment with calcium hydrogen carbonate caused a great adverse effect on cellulose stability, lowering Mw much more and increasing carbonyl groups more than in the untreated sample after aging. Calcium hydrogen carbonate in a mixture of water and ethanol (2:1) resulted in an Mw comparable to that of the untreated sample; hence, neither a stabilization effect nor a negative effect was observed. Immediate suction during spraying of the treatment solution onto the sample could have diminished the horizontal migration of copper ions, but an aqueous treatment on a suction table can still cause color bleeding, which indicates significant migration of copper ions into the paper matrix. With ethanol only, we also observed slight color bleeding. However, the extent was much less than with the pure aqueous treatment, leading to no significant influence on Mw. Therefore, when the verdigris paint is still partially soluble in water, an aqueous treatment has a detrimental effect on cellulose stability rather than a beneficial effect even if it is applied with an additional stabilizing reagent.

\section{Deacidification}

The first trial with calcium hydrogen carbonate in a mixture of water and ethanol (2:1) by spraying was able to stabilize the cellulose degradation slightly, but the second trial of treatment was only comparable to the untreated sample, indicating no significant benefit from the treatment (Figure 4, left). The inconsistent results imply that the spraying application on such a sample on a suction table cannot always promise a positive effect for stabilization. In the case of brushing on the verso or of a floating application of calcium hydrogen carbonate in a mixture, an adverse effect on cellulose stability manifested (Figure 4, left). The treatments caused more hydrolytic degradation and oxidation than the untreated control.

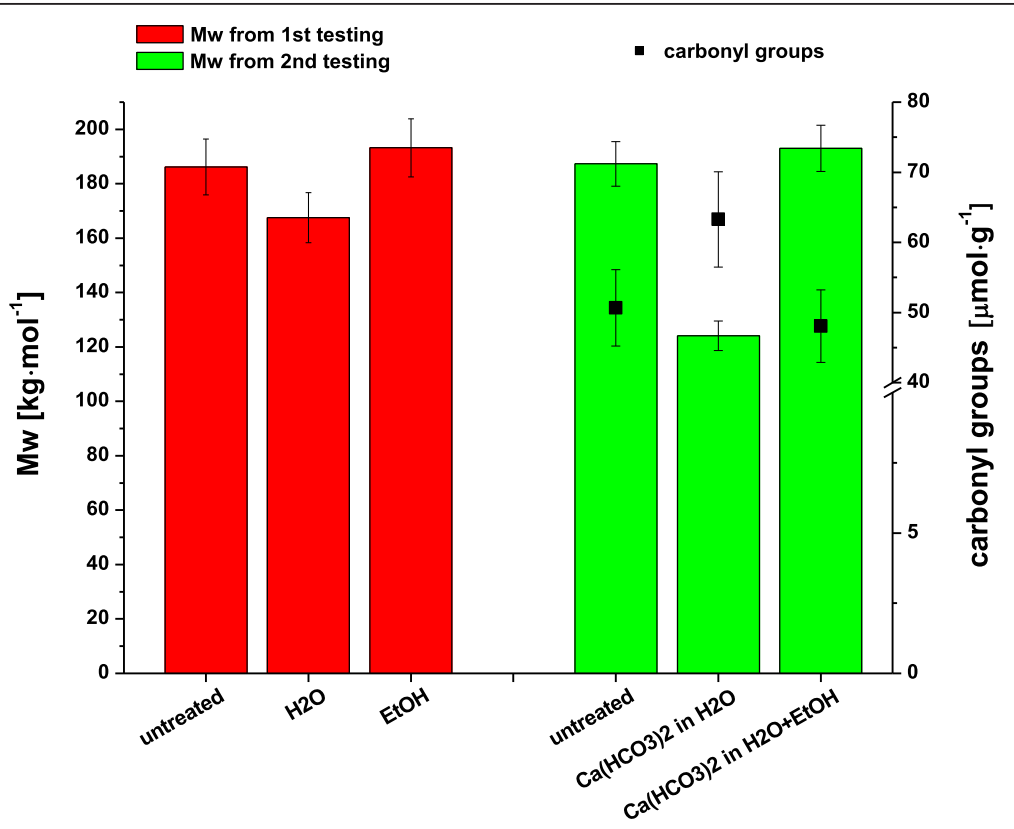

Figure 3 Comparison between pure aqueous treatment and treatment using ethanol or a mixture of water and ethanol. Molar masses and carbonyl groups of the samples after thermally induced accelerated aging. The first test set (left, red) was treated with pure water or pure ethanol, and the second set (right, green) was treated with calcium hydrogen carbonate solution in water or in a mixture of water and ethanol (2:1) prior to accelerated aging. Spraying on a suction table was applied to all samples. 

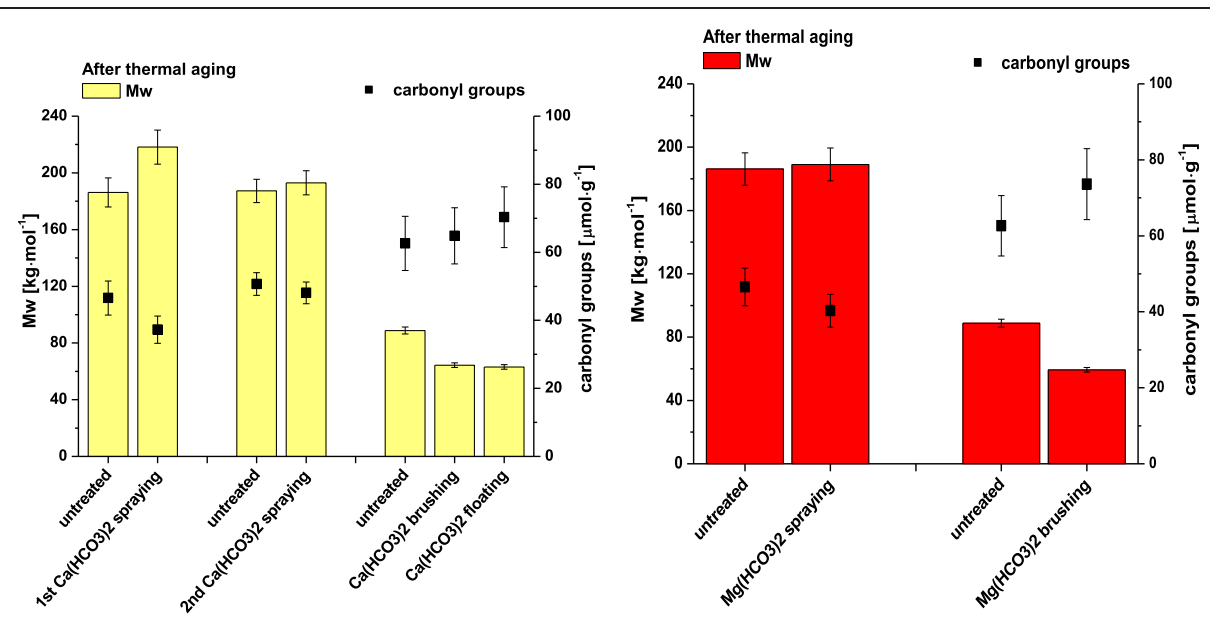

Figure 4 Results of GPC analysis of the deacidified samples. Left - Molar masses and carbonyl groups of the samples treated with $\left.\mathrm{Ca}_{(\mathrm{HCO}}\right)_{2}$ after thermally induced accelerated aging. Right - Molar masses and carbonyl groups of the samples treated with $\mathrm{Mg}_{(}\left(\mathrm{HCO}_{3}\right)_{2}$ after thermally induced accelerated aging.

The results from magnesium hydrogen carbonate in a mixture were similar to those of calcium hydrogen carbonate (Figure 4, right). Therefore, both deacidification treatments hardly stabilized the rag paper with partially soluble verdigris during thermal aging.

The reasons that calcium or magnesium hydrogen carbonate in a mixture did not produce clear beneficial effect can be found in the parameters of the samples and the application method rather than in the alkaline degradation mechanisms. First, partially soluble verdigris made the treatments uncontrollable or negative due to the solution's large water content, resulting in fluctuation of the data or lower $\mathrm{Mw}$ than the untreated sample. The paper substrate utilized in the study was gelatin-sized rag paper. The inhibition of the penetration of alkaline earth salts into the fiber structure by a heavy gelatin size could also have diminished the effect of deacidification treatments (see also discussion on non-aqueous deacidification treatment) since sizing is an important parameter for the permeability of paper [28]. Furthermore, the $\mathrm{pH}$ of the colored area of the sample was still around 6.4 before deacidification. This means that few acidic degradation products were accumulated in the sample after pre-aging; hence, only a limited benefit can be expected from washing with diluted deacidification solution.

The combination of the instability of the solution and the application method may also have contributed to the results. When calcium hydrogen carbonate solution is diluted with ethanol, the concentration of calcium hydrogen carbonate becomes lower, and its solubility may be hindered. Calcium was detected less homogeneously on the surface after calcium hydrogen carbonate treatment in a mixture of water and ethanol (2:1) using a spraying application method on a suction table compared to the treatment in pure water (Figure 5). Considering the one-third lower concentration of calcium hydrogen carbonate in the mixture of water and ethanol (2:1), the relatively more and inhomogeneous precipitation on the surface might indicate that the solubility of calcium hydrogen carbonate was lowered during the preparation and the treatment. When ethanol is mixed in a solution of calcium hydrogen carbonate in water, dissolved $\mathrm{CO}_{2}$ can be immediately released from the solution due to the exothermic reaction, which lowers the solubility of calcium carbonate in the solution. Figure 6 shows that precipitation of calcium carbonate in a mixture of water and ethanol under ambient conditions takes place much faster than in the solution not mixed with ethanol. Thus, relatively greater instability of a calcium or magnesium hydrogen carbonate solution can be expected when it is mixed with ethanol, supporting the observation from SEM-EDS. Depositing the alkaline reserve only on the surface of the paper is not desirable to enhance the long-term efficacy of the deacidification treatment $[29,30]$.

In addition to the conditions of the unstable solution, the influence of the application method cannot be excluded. The $\mathrm{pH}$ of the unpainted area of the sample, i.e., plain rag paper, after deacidification treatments with calcium hydrogen carbonate or magnesium hydrogen carbonate did not exceed $\mathrm{pH}$ 7.5. Considering the $\mathrm{pH} 6.8$ of the paper before treatment, the applied deacidification treatments increased the $\mathrm{pH}$ by around 0.6 units, indicating no sufficient deposit of the alkaline reserve to counteract the acidic degradation products formed during accelerated aging (see Table 2). A low deposit of alkaline reserve can occur due to the original concentration of the solutions, but the application method also plays a role. Among the application methods tested, the brushing application hardly increased the $\mathrm{pH}$, while the spraying application on a suction table and floating application led to a relatively higher increase in $\mathrm{pH}$. Therefore, the brushing application of the deacidification agent 

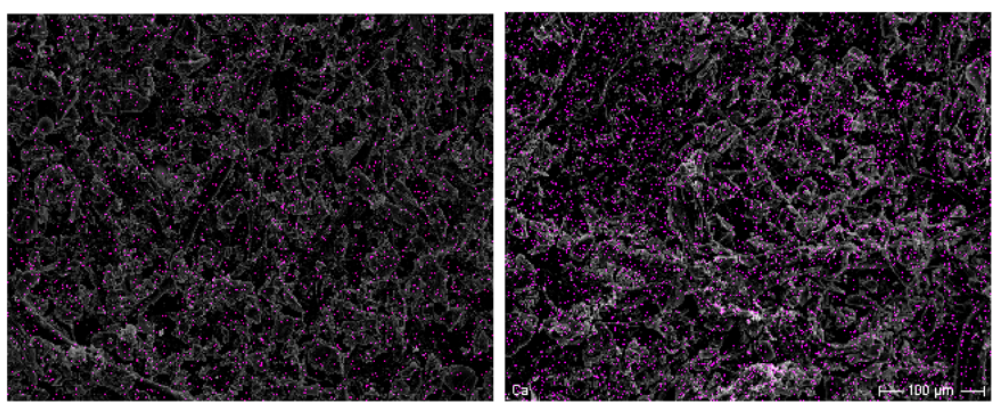

Figure 5 Ca mapping on the surface of calcium hydrogen carbonate-treated samples. Left - Sample after calcium hydrogen carbonate treatment in pure water. The Ca signal was close to the background noise. Right - Sample after calcium hydrogen carbonate treatment in a mixture of water and ethanol (2:1). The overall Ca signal was still weak but relatively higher, and accumulated Ca compounds were observed.

on the verso only caused the migration of copper ions but did not deposit an alkaline active agent and/or wash out any acidic degradation products from the sample, leading to even more degradation than in the untreated control (cf. Figure 4). The floating application was able to introduce relatively more alkaline substances, but it also affected the cellulose stability of the sample adversely, presumably due to the relatively extensive migration of copper ions. Spraying on a suction table was a relatively effective application method for the deacidification treatment of the tested sample, minimizing the migration of copper ions and washing out some degradation products. Nevertheless, it should be noted that the recommended approach would be an immersion application for aqueous deacidification due to the instability of the solutions [18], which could not be applied to the given

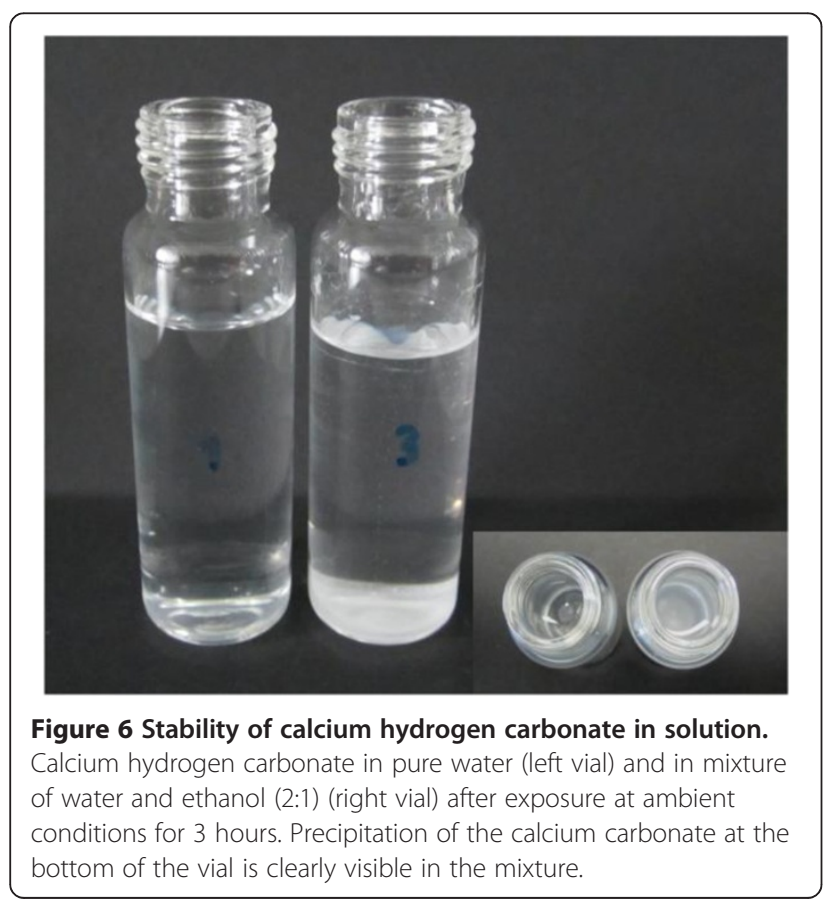

samples for the negative impact induced by copper ion migration.

In summary, the enhanced migration of copper ions by the treatments with high water content in combination with poor and insufficient impregnation of the alkaline reserve into the paper due to the instability of the solutions and heavy gelatin sizing could contribute to the undesirable effect of calcium or magnesium hydrogen carbonate in a mixture of water and ethanol.

For calcium hydroxide in a mixture, only one spraying application was tested, and no beneficial effect was found (data not shown), and no alkaline degradation mechanism due to the relatively high $\mathrm{pH}$ was detected.

Non-aqueous treatment with magnesium propylate by spraying also did not result in any stabilization effect on cellulose degradation but caused an adverse effect (Figure 7). As almost no color bleeding was observed by the naked eye, this result was unexpected. The second trial with consideration of moisture in the environment, involving conditioning and treating of the sample in a chamber with less than $20 \% \mathrm{RH}$, did not improve the situation. No significant beta-elimination or oxidative peeling reaction under alkaline conditions was detectable right after the treatments or after accelerated aging. The degradation was of hydrolytic nature. Hence it can be assumed that no magnesium carbonate was impregnated into the paper matrix due to the heavy gelatin sizing, which contributed to the formation of the compact structure of the rag paper, as shown in Figure 8 (left and right), so no beneficial effect could be obtained.

Table 2 Average pH of plain area of the rag sample without verdigris after deacidification treatment

\begin{tabular}{lllc}
\hline $\begin{array}{l}\text { Before } \\
\text { treatment }\end{array}$ & $\begin{array}{c}\text { After } \\
\mathbf{C a}\left(\mathbf{H C O}_{\mathbf{3}}\right)_{\mathbf{2}}\end{array}$ & $\begin{array}{c}\text { After } \\
\mathbf{M g}\left(\mathbf{H C O}_{\mathbf{3}}\right)_{\mathbf{2}}\end{array}$ \\
\hline \multirow{2}{*}{$6.8 \pm 0.03$} & Spraying on a suction table & $7.40 \pm 0.15$ & $7.43 \pm 0.09$ \\
& Brushing on the verso & $6.95 \pm 0.15$ & $7.07 \pm 0.05$ \\
& Floating & $7.41 \pm 0.01$ & \\
\hline
\end{tabular}




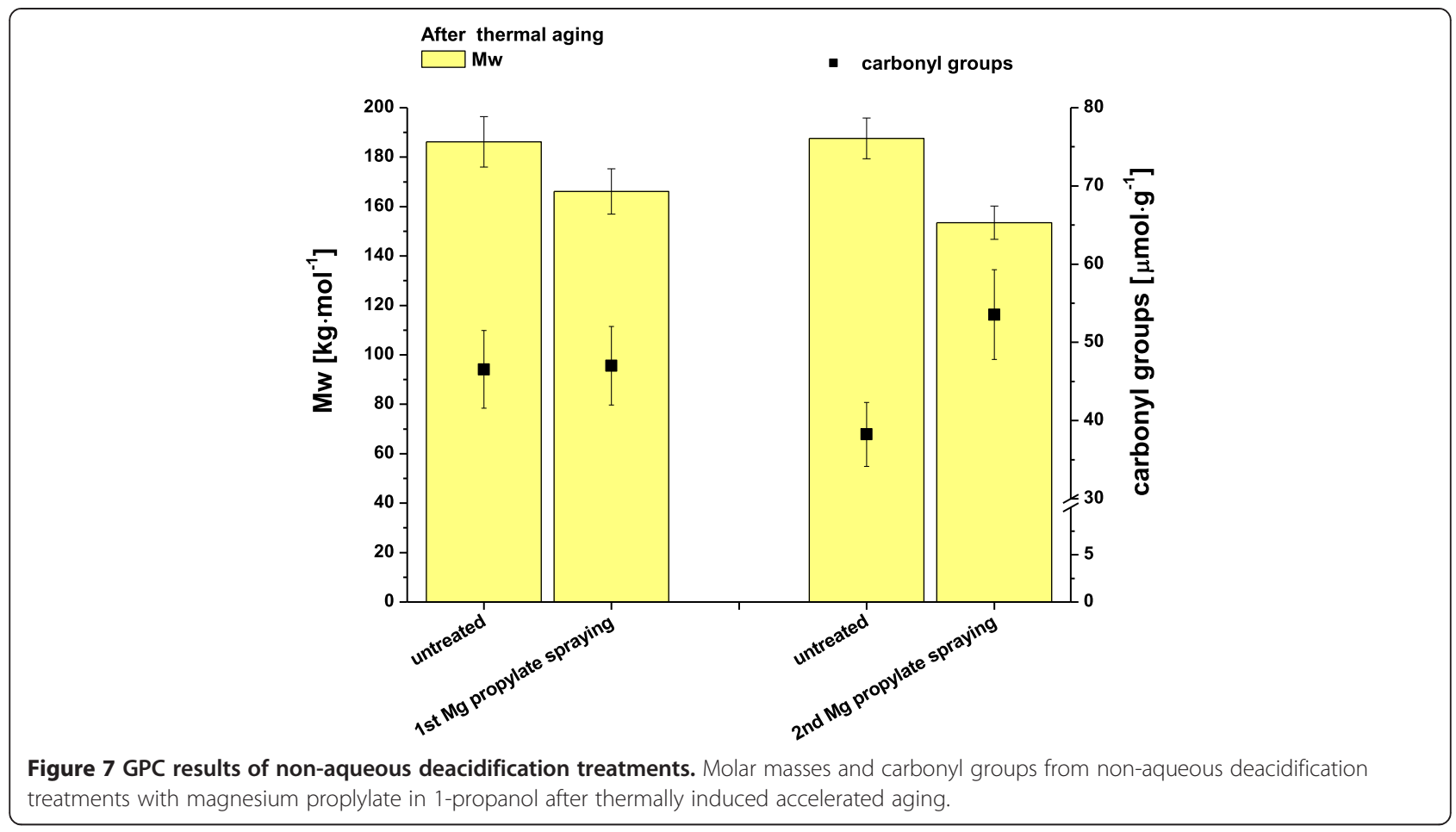

\section{Complexing agents}

Based on previous results on the application of BTA to stabilize the copper alloy gilding in an Osmanic manuscript we have systematically investigated the potential of BTA in copper-induced degradation for the first time [15]. The results obtained with $1 \mathrm{H}$-benzotriazol were depended on the concentration and the application methods. When spraying on a suction table was applied to the sample, only a high concentration, $5 \% \mathrm{w} / \mathrm{v}$, of BTA was effective on the retardation of cellulose degradation in verdigris-containing rag paper. $0.5 \%$ BTA or $0.5 \%$ BTA combined with calcium hydrogen carbonate in a mixture of water and ethanol (2:1) did not give rise to any benefits from the treatment by the spraying application
(Figure 9). The brushing application of 3\% BTA on the verso, on the other hand, was highly effective; the degradation of cellulose was reduced remarkably compared to the untreated control. 3\% BTA treatment by brushing on the verso stabilized better than a 5\% BTA application by spraying on a suction table. This means that the impregnation of BTA into the rag paper matrix by simple brushing can retard the degradation of verdigris-containing rag paper. From Figure 9 it is obvious that BTA strongly inhibits hydrolysis and oxidation. The number of total carbonyls is very high for the untreated control and significantly lowered for the treatment with 3\% BTA. One way of stabilization by BTA is a simple salt formation between BTA and copper ions, since the BTA carries a
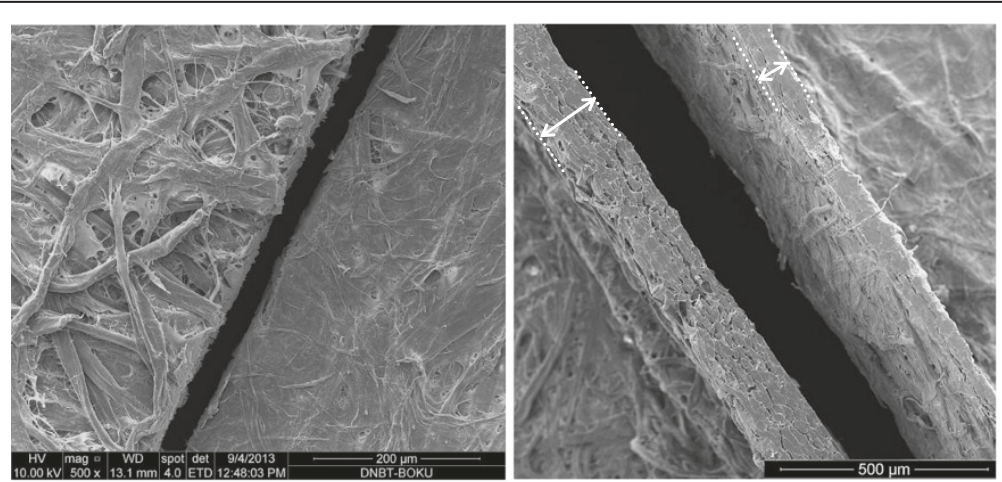

Figure 8 SEM images of two different papers. Left - SEM images of the surface of Whatman no. 1 paper (left) and rag sample paper (right), Right - SEM images of cross-sections of those papers (an arrow indicates the cross-sectioned area). The rag paper used as a sample material in the study showed a much more compact and dense structure compared to Whatman no. 1. 


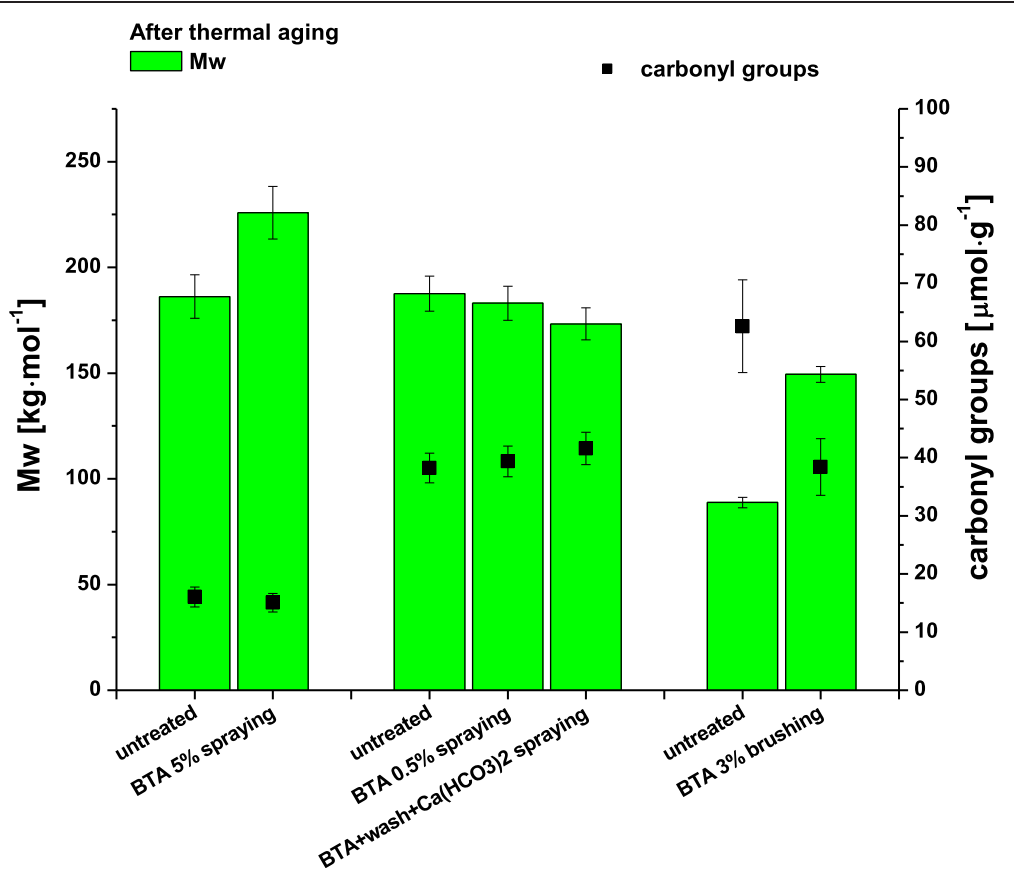

Figure 9 GPC results of BTA treatments. Molar masses and carbonyl groups of the samples treated with $1 \mathrm{H}$-benzotriazol (BTA) in ethanol after thermally induced accelerated aging.

slightly acidic proton $(\mathrm{pKa}=8.37)$. Hence copper ions are immobilized by BTA and cannot take part in other reactions, like formation of hydroxyl radicals, detrimental for cellulose degradation. The fixation of copper ions is also visible in a completely different migration behavior.

The pictures in Figure 10 illustrate how effective BTA is in terms of inhibiting the migration of verdigris. When BTA was impregnated in Whatman paper and the rag paper prior to application of the verdigris paint, it greatly reduced the horizontal migration of the verdigris as soon as the verdigris paint was applied, showing no paint run from the printed area, unlike their control samples without BTA (Figure 10, left). It also inhibited penetration of verdigris into the paper so that no trace of the green color was observed from the verso of the BTA-impregnated Whatman paper (Figure 10, right). This clearly explains why the treatment with BTA was highly effective in stabilizing the copper-induced degradation of cellulose, even under the conditions of the samples that contained verdigris sensitive to a wet treatment. BTA seems to react with copper(II) ions immediately upon contact with verdigris. For metallic copper and its alloys, precise structures of $\mathrm{Cu}$ (I)BTA, $\mathrm{Cu}(\mathrm{II})(\mathrm{BTA})_{2}$ and a chemisorbed structure of BTA on the $\mathrm{Cu} / \mathrm{Cu}_{2} \mathrm{O}$ surface are still being discussed [31,32].

The efficiency of BTA treatment still depends on the application method as well as the sample conditions, e.g., the solubility of verdigris. The spraying of BTA onto a sample on a suction table was less effective since the

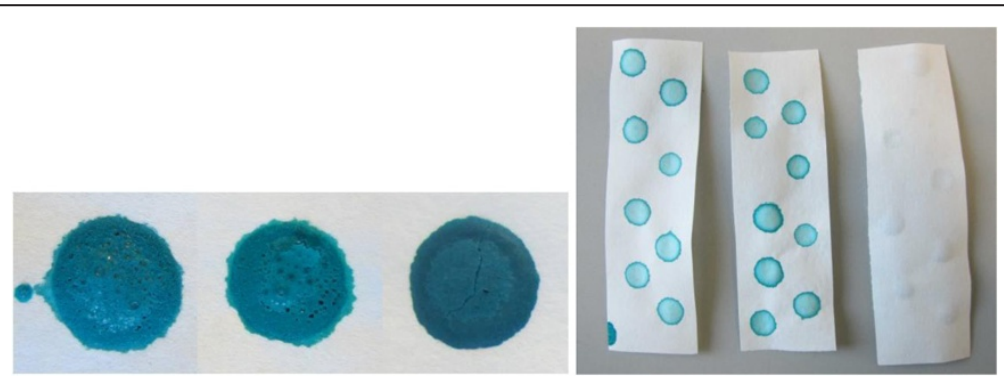

Figure 10 Images of copper-migration test with BTA-impregnated Whatman no. 1 paper and Whatman no. 1 control samples without BTA. From the left, untreated Whatman no. 1 paper, Whatman no. 1 paper treated with a co-solvent without BTA, and Whatman no. 1 paper impregnated with BTA. A remarkable reduction of the migration of verdigris horizontally and vertically is observed in the BTA-impregnated paper. The pictures on the right figure were all taken from the verso. 
excessive removal of BTA may occur, although a certain amount of BTA left in the paper will prevent the migration of copper ions efficiently. Furthermore, directly spraying of BTA on the verdigris paint layer may alter the original color. Therefore, the impregnation of BTA mainly underneath the paint layer by the brushing application on the verso is more desirable, preventing further migration of copper ions as well as minimizing modification of the original verdigris paint layer.

It should be pointed out that BTA causes discoloration of paper itself when it is exposed to light. Therefore, a concentration as low as possible and limited exposure to light are suggested if BTA is used as it is. In other words, objects that are expected to be exhibited frequently must not be treated with BTA.

No calcium phytate treatments brought about stabilization of the degradation of rag paper with verdigris. Application of conventional aqueous calcium phytate followed by calcium hydrogen carbonate treatment, which has proved effective in the stabilization of the paper substrate with iron gall ink [14,33], resulted in more oxidation as well as more hydrolytic degradation of cellulose than in the untreated control (Figure 11).

Spraying of modified calcium phytate in a mixture of water and ethanol generated comparable results for $\mathrm{Mw}$ and carbonyl groups to those of the untreated control, implying that no stable complexing with copper ions could be achieved. A reason that modified calcium phytate treatment was better than pure aqueous calcium phytate is that relatively fewer copper ions were released during the treatment due to its lower water content. The modified calcium phytate followed by calcium hydrogen carbonate treatment caused even more degradation, presumably due to a prolonged treatment time with water-based solution, which led to more migration of copper ions but limited benefit from deacidification, as discussed previously.

The theoretical background of the possibility of chelating $\mathrm{Cu}$ (II) ions by phytic acid or phytate salt is still valid $[34,35]$. However, with the sample composed of heavily sized rag paper and water-sensitive verdigris, the potential of calcium phytate as a complexing agent for coppercontaining paper could not be confirmed. A longer reaction time by immersion or optimization of the conditions of phytate application for chelating $\mathrm{Cu}(\mathrm{II})$ ion is necessary.

\section{Antioxidants}

The TBAB treatment also depended on the application methods. The spraying application of $1 \% \mathrm{w} / \mathrm{v}$ TBAB in ethanol resulted in just comparable $\mathrm{Mw}$ to that of the untreated control after thermal accelerated aging, whereas it retained $\mathrm{Mw}$ significantly better than the untreated control when it was applied by brushing on the verso (Figure 12). This result proves that TBAB can inhibit the copper-catalyzed degradation mechanisms of cellulose not necessarily only in combination with deacidification but also under slightly acidic conditions. This finding is not in agreement with a previous study involving copper pigment by Tse et al. [11]. Taking into account the difficult

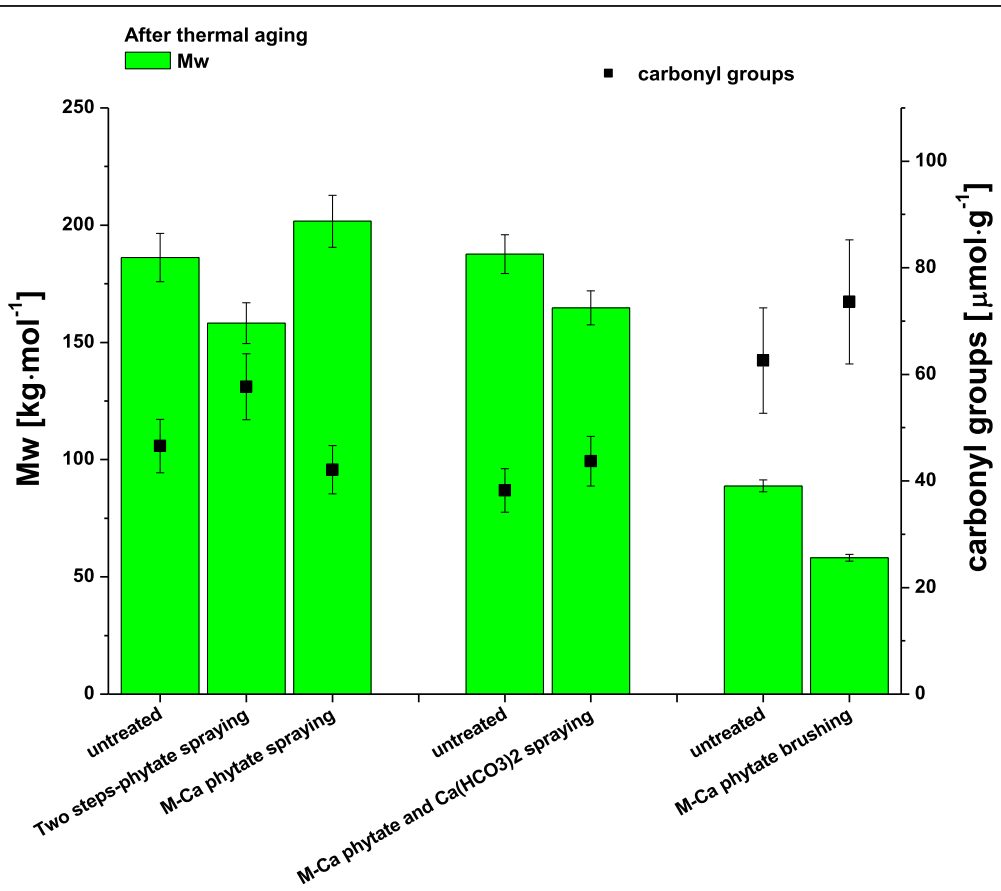

Figure 11 GPC results of phytate treatments. Molar masses and carbonyl groups of the samples treated with modified calcium phyate or two step-calcium phytate treatments after thermally induced accelerated aging. 


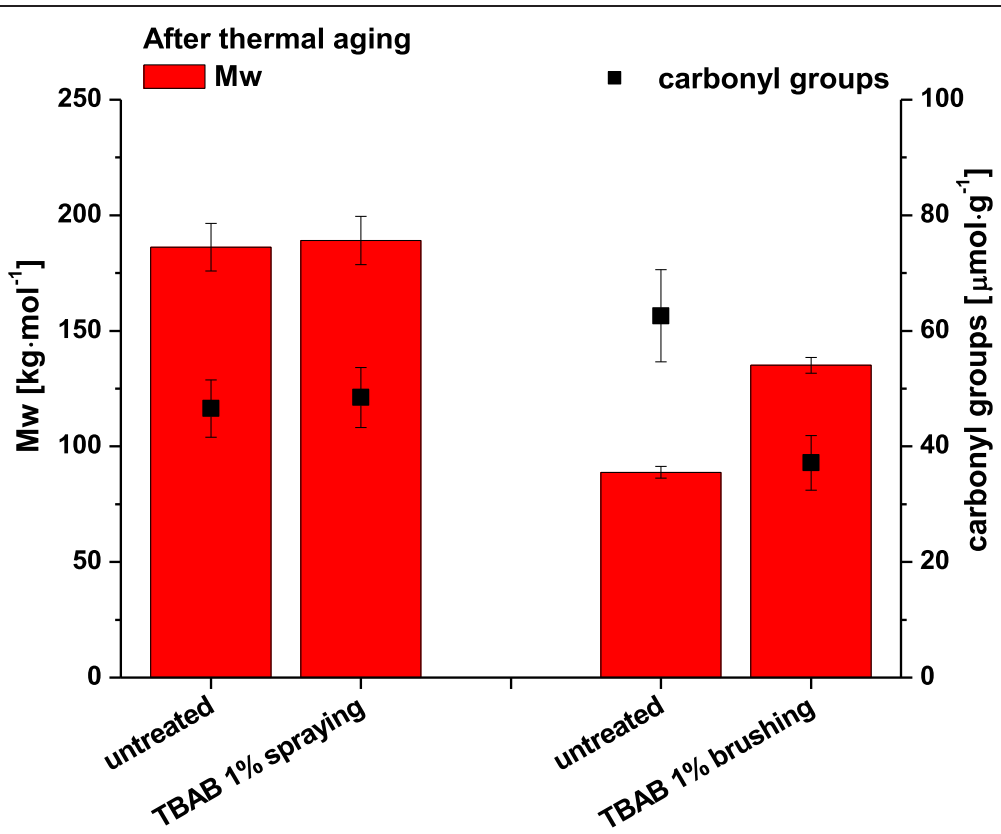

Figure 12 GPC results of TBAB treatments. Molar masses and carbonyl groups of the samples treated with $1 \%$ tetrabutylammonium bromide (TBAB) in ethanol after thermally induced accelerated aging.

conditions of the sample that can hardly be stabilized by a wet chemical treatment, the effect of TBAB in reducing hydrolytic degradation as well as the oxidation of cellulose was still pronounced in this study. The reaction rate of bromides in the reduction of hydroxyl radical production was far lower at $\mathrm{pH} 7$ compared to that at $\mathrm{pH} 9$ [8]. Therefore the underlying mechanism of TBAB reaction as an antioxidant under the conditions of the sample is still not fully understood. In any case, according to previous studies, TBAB treatment in combination with a deacidification treatment seems to be promising for the stabilization of copper-containing paper.

Similar to the case of BTA, its impregnation into the paper matrix, possibly with a minimum intervention of verdigris paint, is important rather than washing it away. An optimum concentration or any pro-oxidative effect at a higher concentration should be investigated further.

Ethyl $p$-hydroxybenzoate (PHB) did not demonstrate any distinctive beneficial effect on the stabilization of verdigris-containing rag paper, though several tests with different concentrations were carried out. The spraying application for PHB proved relatively better since more hydrolytical degradation as well as much more oxidation was visible when the brushing application on the verso was carried out (Figure 13). The PHB showed a rather pro-oxidative effect compared to the untreated control, but due to the high error range of carbonyl groups in the samples, it was not possible to prove it clearly. Although alkyl $p$-hydroxybenzoate was effective when it was added to a deacidification agent at a low concentration [12], the results revealed that a single application of PHB with the given concentrations is not effective.

\section{Light aging}

The trends found after thermal aging did not change much after light aging; samples treated with $1 \%$ PHB were comparable to the untreated control samples. Deacidification treatments with calcium or magnesium hydrogen carbonate in mixtures of water and ethanol (2:1) and modified calcium phytate treatment led to more degradation, agreeing with the results of thermal aging (Figure 14). 3\% BTA in ethanol was the only treatment that showed a clear stabilization effect on verdigris-containing rag paper after light aging (Figure 14). It reduced the chain scission of cellulose and the formation of carbonyl groups compared to the untreated control. Thus, the BTA-Cu complex formed is stable enough to keep copper inactive in catalytic activity under light as well. No significant antioxidant effect was found from a $1 \% \mathrm{w} / \mathrm{v}$ TBAB treatment applied by brushing on the verso after light aging, in contrast to the result of thermal aging. It reduced the hydrolysis and oxidation of cellulose only slightly, which was not significant considering the error range. Under the light source utilized in this study, degradation related to hydrogen abstraction is probable rather than direct photolysis of C-C [36]. The formation of hydroxyl radicals in paper was detected after light exposure [37], but mainly on the surface of the paper that photons can readily reach, especially in the case of the compacted structure of rag paper. 


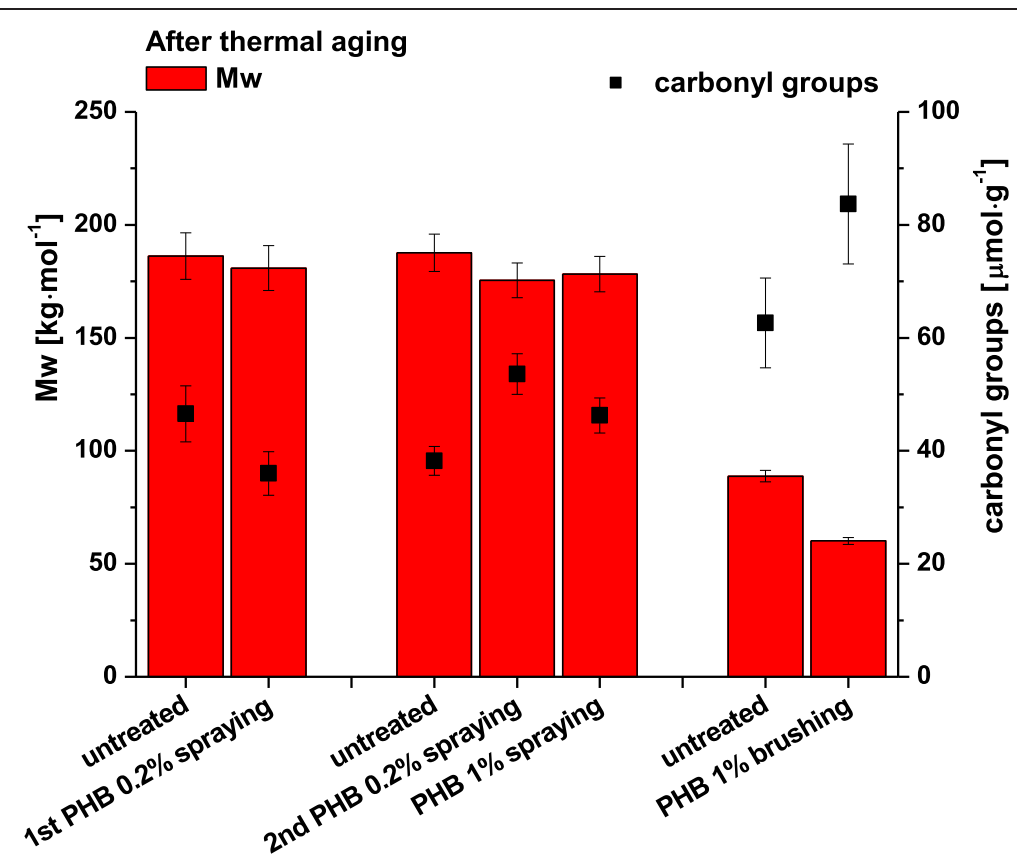

Figure 13 GPC results of PHB treatments. Molar masses and carbonyl groups of the samples treated with ethyl-p-hydroxybenzoate (PHB) in ethanol after thermally induced accelerated aging.

\section{Conclusions}

Our studies on a variety of wet chemical treatments of rag paper with verdigris were able to identify which chemicals and which application methods are effective to stabilize the cellulose and hence the samples. The practical conditions of the sample, i.e., gelatin-sized rag paper with partially soluble verdigris pigment bound in gum arabic narrowed down the potential remedial chemicals to $1 \mathrm{H}$-benzotriazol in ethanol and tetrabutylammonium bromide in ethanol. For both cases, brushing on the verso was efficient, implying that the depositing of these active agents in the paper is necessary. $1 \mathrm{H}$-benzotriazol was

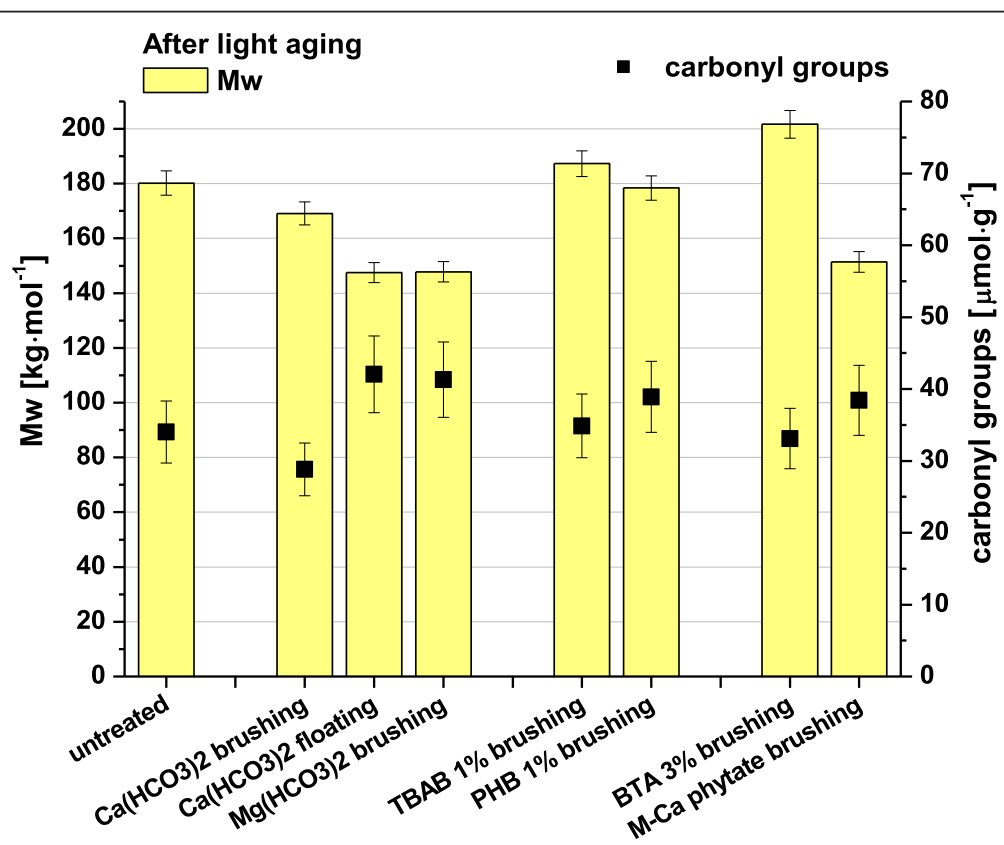

Figure $14 \mathrm{GPC}$ results after light aging. Molar masses and carbonyl groups of the samples treated by brushing on the verso after light aging. 
highly effective in slowing the copper-catalyzed degradation of cellulose under thermal and light aging conditions. Its reaction with copper was efficient and rapid enough to show minimization of the spreading of the verdigris paint visually. Despite the excellent performance of $1 \mathrm{H}-$ benzotriazol, the direct application of $1 \mathrm{H}$-benzotriazol is still immature due to its discoloration of the paper under light. Treatment with tetrabutylammonium bromide in ethanol alone also contributed significantly to the stabilization of the sample paper. This proves that it can be employed without a deacidification treatment, which makes it more versatile in application to the treatments of the paper object.

High water content in treatment solutions generated the uncontrollable migration of copper ions into the paper, completely cancelling out the benefits of active agents. For example, calcium or magnesium hydrogen carbonate in the water and ethanol mixture (2:1) did not demonstrate any stabilization of the sample but exhibited more hydrolytic degradation and oxidation than the untreated sample. The instability of the solutions with limited application methods that could be performed due to the soluble pigment and inhibition of the impregnation of alkaline active substances by heavy gelatin sizing could contribute to the adverse effect of the treatments.

The results above were generated from artificially pre-aged rag paper samples under the conditions given, not from naturally-aged historic rag paper with verdigris. Based on these known conditions of the samples reasons for adverse effects of some chemical treatments could be discussed more clearly. The status of the verdigris paint and the paper substrate in addition to its overall degradation state has to be thoroughly examined to determine the respective treatment to be performed. Overall this will minimize undesired outcomes and enhance long-term efficacy of the treatment.

\section{Competing interests}

The authors declare that they have no competing interests.

\section{Authors' contributions}

KA performed accelerated aging and analyses and prepared the manuscript. $\mathrm{AH}$ performed the treatments. $\mathrm{CH}$ coordinated the conservation part and managed the project. UH performed accelerated aging. AP coordinated the scientific part and helped to draft the manuscript. All authors read and approved the final manuscript.

\section{Acknowledgements}

We thank our colleagues at the University of Natural Resources and Life Sciences, Vienna, and the Institute for Conservation at the Austrian National Library in Vienna. We appreciate especially Prof. Mirjana Kostic at the University of Belgrade for optimization of the modified calcium phytate and Mag. Ina Faerber for preparation of the samples. The financial support of the Austrian Ministry of Science and Research in the forMuse program and of the Christian Doppler Laboratory "Advanced Cellulose Chemistry and Analytics" is gratefully acknowledged.

\section{Author details}

'Department of Chemistry, University of Natural Resources and Life Sciences, Muthgasse 18, 1190 Vienna, Austria. ${ }^{2}$ Institute for Conservation, Austrian National Library, Josefsplatz 1, 1015 Vienna, Austria.
Received: 18 December 2013 Accepted: 16 May 2014

Published: 23 May 2014

\section{References}

1. Bicchieri M, Pepa S: The degradation of cellulose with ferric and cupric ions in a low-acid medium. Restaurator 1996, 17:165-183.

2. Calvini P, Gorassini A: The degrading action of iron and copper on paper a FTIR-deconvolution analysis. Restaurator 2002, 23:205-221.

3. Strlič $\mathrm{M}$, Kolar J, Pihlar B: The effect of metal ion, $\mathrm{pH}$ and temperature on the yield of oxidising species in a Fenton-like system determined by aromatic hydroxylation. Acta Chim Slov 1999, 46:555-566.

4. Šelih VS, Strlič M, Kolar J, Pihlar B: The role of transition metals in oxidative degradation of cellulose. Polym Degrad Stab 2007, 92:1476-1481.

5. Strlič M, Kolar J, Šelih VS, Kočar D, Pihlar B: A comparative study of several transition metals in Fenton-like reaction systems at circum-neutral $\mathrm{pH}$. Acta Chim Slov 2003, 50:619-632.

6. Kolar J, Strlič M, Budnar M, Malešič J, Šelih VS, Simčič J: Stabilisation of corrosive iron gall inks. Acta Chim Slov 2003, 50:763-770.

7. Malešič J, Kočar D, Balažic Fabjan A: Stabilization of copper- and iron-containing papers in mildly alkaline environment. Polym Degrad Stab 2012, 97:118-123.

8. Malešič J, Strlič M, Kolar J, Polanc S: The influence of halide and pseudo-halide antioxidants in Fenton-like reaction systems containing copper (II) ions. J Mol Catal A Chem 2005, 241:126-132.

9. Malešič J, Kolar J, Strlič M, Polanc S: The influence of halide and pseudo-halide antioxidants in Fenton-like reaction systems. Acta Chim Slov 2005, 53:450-456.

10. Maitland C: Where archival and fine art conservation meet: antioxidant and deacidification treatment of corrosive copper wallpapers and copper containing iron gall inks. Book Pap Group Annu 2009, 28:37-46.

11. Tse S, Trojan-Bedynski M, St-Jacques D: Treatment considerations for the Haggadah Prayer Book: evaluation of two antioxidants for treatment of copper-containing inks and colorants. Book Pap Group Annu 2012, 31:87-98.

12. Henniges $U$, Banik $G$, Potthast $A$ : Comparison of aqueous and nonaqueous treatments of cellulose to reduce copper-catalyzed oxidation processes. Macromol Symp 2006, 232:129-136.

13. Meyer F, Neumann A: Recombinant proteins: a new material for the chemical stabilisation of copper pigment corrosion on paper? Restaurator 2009, 30:96-130.

14. Potthast A, Henniges $U$, Banik G: Iron gall ink-induced corrosion of cellulose: aging, degradation and stabilization. Part I: model paper studies. Cellulose 2008, 15:849-859.

15. Faerber I: Kupferfraß auf Papier. PapierRestaurierung 2007, 8:21-29.

16. Williams JC, Fowler CS, Lyon MS, Merrill TL: Metallic Catalysts in the Oxidative Degradation of Paper. In Preservation of Paper and Textiles of Historic and Artistic Value. Advances in Chemistry Series 164. Edited by Williams JC. Washington: American Chemical Society; 1977:37-67.

17. Shahani CJ, Hengemihle FH: Effect of some deacidification agents on copper-catalyzed degradation of paper. 1995, [http://www.loc.gov/ preservation/resources/rt/copper.pdf].

18. Smith AW: Aqueous Deacidification of Paper. In Paper and Water: A Guide for Conservators. Edited by Banik G, Brückle I. Oxford: ButterworthHeinemann; 2011:341-388.

19. Potthast A, Henniges U, Hofmann C, Faerber I: Analysis of Copper-ion Degraded Paper: Study on Parameters for the Sample Materials to Evaluate Selected Treatments. In Abstracts of the XII ${ }^{\text {th }}$ IADA International Congress. Bern, Swiss: IADA; 2011:25.

20. Huhsmann $\mathrm{E}$, Hähner $\mathrm{U}$ : Work standards for the treatment of $18^{\text {th }}$ and $19^{\text {th }}$ century iron gall ink documents with calcium phytate and calcium hydrogen carbonate. Restaurator 2008, 29:274-319.

21. Reissland B: Ink corrosion: aqueous and non-aqueous treatment of paper objects—state of the art. Restaurator 1999, 20:167-180.

22. ISO-The International Organization for Standardization (ISO): Paper and Board - Accelerated Aging Part3: Moist Heat Treatment at $80^{\circ} \mathrm{C}$ and $65 \%$ Relative Humidity, ISO 5630:1996. Geneva: ISO; 2003.

23. Röhrling J, Potthast A, Rosenau T, Lange T, Ebner G, Sixta H, Kosma P: A novel method for the determination of carbonyl groups in cellulosics by fluorescence labeling. 1. Method development. Biomacromolecules 2002, 3:959-968. 
24. Röhrling J, Potthast A, Rosenau T, Lange T, Borgards A, Sixta H, Kosma P: A novel method for the determination of carbonyl groups in cellulosics by fluorescence labeling. 2. Validation and applications. Biomacromolecules 2002, 3:969-975.

25. Potthast A, Röhrling J, Rosenau T, Borgards A, Sixta H, Kosma P: A novel method for the determination of carbonyl groups in cellulosics by fluorescence labeling. 3. Monitoring oxidative processes. Biomacromolecules 2003, 4:743-749.

26. Strlič M, Kolar J, Kocar D, Drnovsek T, Šelih VS, Susic R, Pihlar B: What is the $\mathrm{pH}$ of alkaline paper? e-PreservationSci 2004, 1:35-47.

27. TAPPI_-Technical Association of the Pulp and Paper Industry: TAPPI Test Methods. Hydrogen ion Concentration (pH) of Paper Extracts, TAPPI 509 om.02. Atlanta, GA: TAPPI PRESS; 2004

28. Banik G, Brückle I, Lacher R, Wegele G: Effect of Sizing on Paper-Water Interactions. In Paper and Water: A Guide for Conservators. Edited by Banik G, Brückle I. Oxford: Butterworth-Heinemann; 2011:145-171.

29. Ahn K, Banik G, Potthast A: Sustainability of mass-deacidification-part 2: evaluation of alkaline reserve. Restaurator 2012, 33:48-75.

30. Ramin M, Andres H, Blüher A, Reist M, Wälchli M: Paper de-acidification. J Pap Conserv 2009, 10:17-25

31. Walker R: Benzotriazole: a corrosion inhibitor for antiques. J Chem Educ 1980, 57:789-791.

32. Milosev I, Finsgar M: Inhibition of copper corrosion by 1,2,3-benzotriazole: a review. Corros Sci 2010, 52:2737-2749.

33. Neevel JG: Phytate: a potential conservation agent for the treatment of ink corrosion caused by iron gall inks. Restaurator 1995, 16:143-160.

34. Tsao CT, Zheng Y, Lu J, Gong CS: Adsorption of heavy metal ions by immobilized phytic acid. App/ Biochem Biotechnol 1997, 63-65:731-741.

35. Li Y, He J-B, Zhang M, He X-L: Corrosion inhibition effect of sodium phytate on brass in $\mathrm{NaOH}$ media. Potential-resolved formation of soluble corrosion products. Corros Sci 2013, 74:116-222

36. Feller RL: Accelerated Aging: Photochemical and Thermal Aspects. USA: The Getty Conservation Institute; 1994.

37. Malešič J, Kolar J, Strlič M, Kočar D, Fromageot D, Lemaire J, Haillant O: Photo-induced degradation of cellulose. Polym Degrad Stab 2005, 89:64-69.

doi:10.1186/2050-7445-2-12

Cite this article as: Ahn et al:: Investigation of the stabilization of verdigris-containing rag paper by wet chemical treatments. Heritage Science 2014 2:12

\section{Publish with ChemistryCentral and every scientist can read your work free of charge \\ "Open access provides opportunities to our colleagues in other parts of the globe, by allowing anyone to view the content free of charge." \\ W. Jeffery Hurst, The Hershey Company. \\ - available free of charge to the entire scientific community \\ - peer reviewed and published immediately upon acceptance \\ - cited in PubMed and archived on PubMed Central \\ - yours - you keep the copyright \\ Submit your manuscript here: \\ http://www.chemistrycentral.com/manuscript/<smiles>c1ccccc1</smiles> 